\title{
Polymeric Mesoporous Silica Nanoparticles for Combination Drug Delivery In vitro
}

\author{
Thashini Moodley ${ }^{1}$ (D), Moganavelli Singh $1, * \mathbb{D}$ \\ 1 Nano-Gene and Drug Delivery Laboratory, Discipline of Biochemistry, University of KwaZulu-Natal, Private Bag \\ X54001, Durban, South Africa \\ * Correspondence: singhm1@ukzn.ac.za;
}

Scopus Author ID 37095919000

Received: 11.11.2020; Revised: 15.12.2020; Accepted: 17.12.2020; Published: 20.12.2020

\begin{abstract}
Despite the recent advances and development of conventional cancer therapy strategies, treatments often lack specificity, resulting in low therapeutic efficiency, cancer recurrence, and drug resistance. With the advent of nanotechnology, nanoparticle-based delivery systems have steadily gained interest. The key to using any drug delivery system is its' relative cytotoxicity, pharmacokinetics, and downstream immunological effects that may arise upon repetitive exposure. Among the nanoparticle systems, mesoporous silica nanoparticles (MSNs) have received favorable attention as potential drug delivery platforms. This study aimed to synthesize and functionalized MSNs with chitosan and polyethyleneglycol for improved stability, efficient drug loading, and drug release. These polymerized MSNs were physicochemically and morphologically characterized and assessed for their dual-drug [doxorubicin (DOX)/5-fluoruracil (5-FU)] loading, drug release kinetics, and anticancer activity in vitro. MSNs ranged from $35-70 \mathrm{~nm}$ in size, with a high surface area $\left(809.44 \mathrm{~m}^{2} / \mathrm{g}\right)$ and a large pore volume $\left(1.74 \mathrm{~cm}^{2} / \mathrm{g}\right)$. The DOX/5-FU co-loading produced a potent dual-drug formulation with good $\mathrm{pH}$-responsive release profiles, high percentage release, especially from PEGylated MSNs, and significant anticancer activity the breast adenocarcinoma (MCF-7) and cervical cancer (HeLa) cells. This combination therapy's favorable outcomes suggest an improved therapeutic strategy that warrants investigation in an in vivo model.
\end{abstract}

Keywords: mesoporous silica nanoparticles; anticancer; doxorubicin; 5- fluorouracil; drug delivery; drug release.

(c) 2020 by the authors. This article is an open-access article distributed under the terms and conditions of the Creative Commons Attribution (CC BY) license (https://creativecommons.org/licenses/by/4.0/).

\section{Introduction}

The metastatic disease of cancer is of immense concern and a challenge for researchers and society. Studies predict formidable global increases in the number of cases, especially in developing countries, within the next decade [1]. The drawbacks of conventional cancer therapy, especially with chemotherapy, are a consequence of the unique heterogeneity of cancer and the lack of multi-faceted treatment approaches. This has seen the advancement of chemotherapeutic or radiotherapy-induced toxicities and multi-drug resistance, leading to distant metastases, locoregional recurrences, and the recurrence of primary tumors [2]. Despite the burgeoning development and screening of novel drugs and biomolecules that may possess the anticancer activity and the persistent improvement to current conventional cancer therapeutic strategies, there is an indisputable niche for the introduction of improved therapeutic platforms that address the significant concerns of failing drug dosing and its resultant detrimental effects [3]. There has been a favorable shift to non-viral delivery vehicles 
due to safety concerns [4], with the combination of anticancer drugs together with inorganic nanoparticles (NPs) have piqued the interest of researchers [5]. Inorganic NPs display advantages over organic vectors regarding their nano-size, good stability, and relative ease of synthesis and modification [4].

Drug targeting by inorganic nanoparticles (NPs) offers advantages such as reduced drug dosages, enhanced pharmacological effects, minimized side effects, and increased drug stability [6]. Combination drug-targeting nanosystems promise increased efficiency, improved therapeutic activity, and reduced side effects associated with drug-induced toxicities and resistance. Thus, a nanocarrier can deliver combined medications in a single dose or "polypill" formulation is attractive [7]. Nanotechnology has, to date, produced an array of NPs that may be promising candidates for application in nanomedicine. These include gold [8-11], silver [1214], hydrotalcite [15,16], selenium [17-19], mesoporous silica [20-22], iron oxides or nano ferrites [23,24], and bimetallic NPs [5,25]. From the above plethora of drug delivery nanocarriers available, mesoporous silica nanoparticles (MSNs) possess a thermal and chemically stable framework with a porous honeycomb-like structure for high drug loading controlled release functions have gained interest [22]. The tuning of the particle size and modification of the interfacial surface are two of the most malleable properties of MSNs. These parameters affect cellular uptake, biocompatibility, stability, and pharmacokinetic fate in vitro.

Polyethyleneglycol (PEG) coating of NPs reduces interparticle attractive forces and provides a protective hydrophilic shield against biological components $[9,26]$. This increases the nanosystem's pharmacokinetic fate, improves its circulation half-life, and increases the bound drug's solubility and stability [27]. The biodegradable biopolymer chitosan (CHIT) chosen as a cationic coating agent increases the dissolution rate of poorly soluble drugs, has favorable mucoadhesive properties, drug targeting, and low toxicity in vivo [28]. When conjugated to an NP via ionic gelation, CHIT, a polyamine, forms a polyelectrolyte complex (PEC), which increases intestinal absorption. This favorable combination of CHIT and PEG to form a PEC, has been utilized for efficient drug loading and release in hydrogel and microsphere formulations [29].

In this study, CHIT and PEG functionalized MSNs, were assessed for enhanced loading and release of a combined DOX/5-FU formulation, with improved biocompatibility and cytotoxicity in vitro.

\section{Materials and Methods}

\subsection{Materials.}

Tetraethyl orthosilicate (TEOS, $\left.\mathrm{Si}\left(\mathrm{OCH}_{2} \mathrm{CH}_{3}\right)_{4}\right)$, Triton X-100 (TX100), cetyltrimethylammonium bromide (CTAB, 99\%), polyethyleneglycol $2000\left(\mathrm{PEG}_{2000}\right)$, chitosan (75-85 \% deacetylated), sodium tripolyphosphate (TPP), Tweens 20, ammonia solution (28$30 \%$ ), sulphuric acid, sodium carbonate $\left.\left(\mathrm{Na}_{2} \mathrm{CO}_{3}\right), \mathrm{ES}\right)$, 5-fluorouracil (5-FU), sulforhodamine B (SRB) and deuterium oxide were all purchased from Sigma Aldrich (St Lois, USA). Eagle's minimum essential medium (EMEM), fetal bovine serum (FBS), penicillin/streptomycin solution $(10,000 \mathrm{U} / \mathrm{mL})$, and trypsin-EDTA (0.25\% trypsin, $0.1 \%$ EDTA) were obtained from Lonza (Viviers, Belgium). Phosphate-buffered saline (PBS) tablets were purchased from Calbiochem, Canada. The MTT salt (3-(4,5-dimethylthiazol-2-yl)- 2,5-diphenyltetrazolium bromide) and trichloroacetic acid (TCA) were purchased from Merck, Darmstadt, Germany. Human embryonic kidney (HEK293), cervical carcinoma (HeLa), breast adenocarcinoma 
(MCF-7) and colon adenocarcinoma (Caco-2) cells were obtained from the American Type Culture Collection (Manassas, VA, USA). Corning Inc., Corning, NY, USA provided all sterile plastic and ultrapure $18 \mathrm{M} \Omega$ water being used in reactions.

\subsection{Synthesis and functionalization of MSNs.}

MSNs were synthesized by a sol-gel reaction and functionalized as previously published by the authors [20,21]. Briefly, TEOS $(500 \mu \mathrm{L}), \mathrm{CTAB}(100 \mathrm{mg})$, and $2 \mathrm{M} \mathrm{NaOH}$ $(350 \mu \mathrm{L})$ were mixed and incubated for $2 \mathrm{~h}$, followed by centrifugation $(4000 \mathrm{rpm})$, an ethanol and water wash, and an acidic methanol removal of unreacted CTAB overnight. The pelleted MSNs were calcined for 24 hours at $70{ }^{\circ} \mathrm{C}$. For functionalization with CHIT, MSN (200 mg) was added to CHIT (15 mg in $40 \mathrm{~mL}$ acetic acid, $10 \% \mathrm{v} / \mathrm{v}$ ), stirred at ambient temperature for $24 \mathrm{~h}$, centrifuged, washed with absolute ethanol followed by water, and dried at $60{ }^{\circ} \mathrm{C}$ for 24 h. For PEG and CHIT functionalization, CHIT (22.5 mg) and PEG2000 [179 mg (2\%) or 449 $\mathrm{mg}(5 \%)]$ were added to $30 \mathrm{~mL}$ acetic acid (2\%), followed by the addition of $15 \mathrm{~mL}$ TPP $(7.725$ $\mathrm{mg}$ ). This was combined with MSN (300 mg), stirred for $24 \mathrm{~h}$ at room temperature, and centrifuged (1000 rpm, $30 \mathrm{~min}$ ) to obtain the final products (2\% and 5\% PEG-CHIT-MSN), which were washed and dried at $60{ }^{\circ} \mathrm{C}$ for $24 \mathrm{~h}$.

\subsection{Formulation of drug-loaded MSNs (D-MSNs).}

The functionalized MSNs (150 mg) was added to $5 \mathrm{~mL}$ water containing $10 \mathrm{mg}$ DOX and $15 \mathrm{mg}$ 5-FU to allow the drug molecules to absorb into the MSN framework by hydrophobic and electrostatic interactions. At 0 and 30 hours, $1 \mathrm{~mL}$ of the drug solution was extracted, centrifuged. The supernatant was analyzed by UV-vis spectroscopy at 266 and 488 $\mathrm{nm}$, respectively. The precipitate was returned to the solution. The final D-MSNs were centrifuged, washed, and calcined as previously. Drug loading was calculated as in equation 1.

$$
\text { Loading capacity }(w t \%)=\frac{\text { Mass of drugs in } M S N s}{\text { Final Mass of D }-M S N S}
$$

\subsection{Characterisation of nanoparticles and nanocomplexes.}

\subsubsection{Fourier Transform Infra-Red Spectroscopy (FTIR).}

A Bruker Alpha ATR Fourier Transform Infrared Spectroscopy (Bruker, South Africa) was used to obtain the FTIR spectra, from $4000 \mathrm{~cm}^{-1}$ to $400 \mathrm{~cm}^{-1}$, at a resolution of $4 \mathrm{~cm}^{-1}$. This served to confirm the presence of characteristic bonds and functional groups.

\subsubsection{Nanoparticle Tracking Analysis (NTA).}

Hydrodynamic size and zeta potential of the MSNs were analyzed using NTA (NanoSight NS500, Malvern Instruments Ltd., Worcestershire, UK). NTA software v3.0 was used to determine the hydrodynamic diameters (calculated from particle tracks using the Stokes-Einstein equation) and the zeta potential using Smoluchowski approximation. Data are presented as mode \pm standard error. 


\subsubsection{Transmission Electron Microscopy (TEM).}

Samples were placed on a carbon-coated copper grid, air dried, and viewed using a JEOL-JEM T1010 electron microscope (JEOL, Tokyo, Japan) at an accelerating voltage of 100 $\mathrm{kV}$. The resulting images were captured and analyzed using the iTEM Soft Imaging Systems (SIS).

2.4.4. Nitrogen adsorption and desorption isotherms.

Isotherms were obtained at $77 \mathrm{~K}$ using a Micrometrics Tri-Star II 3030 version 1.03 instrument. The Brunauer-Emmet-Teller (BET) equation was used to determine surface area, the single point method to determine pore volume, the Barrett-Joyner-Halenda (BJH) model, and the desorption branch of the isotherm to determine pore size distribution [30].

\subsection{Drug release studies.}

To estimate the amount of drug liberated from the D-MSN nanocomplex, $5 \mathrm{mg}$ of the D-MSNs were dispersed in $15 \mathrm{~mL}$ of PBS at $\mathrm{pH} 4.2$ and 7.4, respectively, with stirring at $37^{\circ} \mathrm{C}$. At regular intervals over 72 hours, $0.5 \mathrm{~mL}$ of the MSN suspension was centrifuged and analyzed by UV-vis spectroscopy at 266 and $488 \mathrm{~nm}$, respectively. Experiments were conducted in triplicate. Drug release was calculated using equation 2:

$$
\% R_{t}=\frac{C_{t} \cdot V_{1}+V_{2} \cdot\left(C_{t-1}+C_{t-2}+\cdots+C_{0}\right)}{W_{0} \cdot L} \times 100 \%
$$

Where $C_{t}$ is the drug concentration at time interval $\mathrm{t}, C_{t-1}+C_{t-2}$ are drug concentrations before time $\mathrm{t}\left(C_{0}=0\right) . V_{1}$ is the total volume of the drug release bath $(15 \mathrm{~mL})$; and $V_{2}$ is the volume analysed $(0.5 \mathrm{~mL}) . W_{1}$ is the initial weight of the D-MSNs $(0.005 \mathrm{~g})$, and $L$ is the drug loading capacity of the D-MSNs (from equation 1).

\subsection{Cell viability assay.}

Cell viability was evaluated using the MTT assay [31]. HEK293, Caco-2, MCF-7, and HeLa cells were seeded at a density of $1 \times 10^{4}$ cells/well in 96 well plates and incubated at $37^{\circ} \mathrm{C}$ in $5 \% \mathrm{CO}_{2}$ for $24 \mathrm{~h}$. After that, cells were treated in triplicate with D-MSNs $(20,50$, and $100 \mu \mathrm{g} / \mathrm{mL}$ ), MSNs, and the free drugs, and incubated for $48 \mathrm{~h}$, with untreated cells as the control. After that, the medium was replaced with $10 \%$ (v/v) MTT $(5 \mathrm{mg} / \mathrm{mL}$ in PBS stock) in $200 \mu \mathrm{L}$ fresh medium, incubated at $37^{\circ} \mathrm{C}$ for $4 \mathrm{~h}$, followed by the addition of $100 \mu \mathrm{L}$ of DMSO for solubilization of the purple formazan crystals. Absorbance at $540 \mathrm{~nm}$ was determined in a Mindray MR-96A microplate reader (Vacutec, Hamburg, Germany). Cell viability (\%) was calculated as in equation 3:

$$
\% \text { Cell Survival }=\frac{A_{540 \mathrm{~nm}} \text { of treated cells }}{A_{540} \text { control cells }(\text { untreated })} \times 100 \%
$$

\subsection{Apoptosis assay.}

This assay was conducted by visualizing cells stained with the vital dyes acridine orange and ethidium bromide. Cells were seeded into a 24 -well plate at a density of $1.5 \times 10^{5}$ cells/well and maintained as previously. Cells were treated $(50 \mu \mathrm{L} /$ well $)$ as in 2.5 for $48 \mathrm{~h}$, in 
triplicate, with untreated cells as the control. After that, the medium was removed, cells washed with $200 \mu \mathrm{L}$ PBS, followed by the addition of $12 \mu \mathrm{L}$ dye (AO:EB, 1:1 v/v, $1 \mathrm{mg} / \mathrm{mL}$ ) over 5 minutes. The excess dye was then removed, cells washed with $200 \mu \mathrm{L}$ PBS, and viewed under an Olympus inverted fluorescence microscope (200X magnification), fitted with a CC12 fluorescence camera (Olympus Co., Tokyo, Japan).

\subsection{Cell cycle analysis.}

Cells were seeded into a 24 -well plate at a density of $1.5 \times 10^{5}$ cells/well and maintained as previously. Cells were treated $(50 \mu \mathrm{L} /$ well $)$ as in 2.5 for $48 \mathrm{~h}$, in triplicate, with untreated cells as the control. Following incubation, the cells were pelleted at $300 \mathrm{X} \mathrm{g}$ for 5 minutes, washed with PBS, and resuspended in $200 \mu \mathrm{L}$ cold ethanol $(70 \% \mathrm{v} / \mathrm{v})$. Cells were then incubated at $-20^{\circ} \mathrm{C}$ overnight, followed by centrifugation and a PBS wash. Finally, $200 \mu \mathrm{L}$ of Muse ${ }^{\circledR}$ Cell Cycle reagent (propidium iodide, RNase A; Merck, Darmstadt, Germany), was added to the cells, which were incubated for 30 minutes at room temperature. Samples were analyzed using a Muse ${ }^{\mathrm{TM}}$ Cell Analyzer (Luminex, TX, USA).

\subsection{Statistical analysis.}

Data are presented as mean \pm SD (standard deviation). Statistical analyses were performed using ANOVA (one-way analysis of variance) (GraphPad Prism version 6, GraphPad Software Inc., USA). The Dunnett multiple comparison and Tukey honestly significant difference (HSD) tests were used as post hoc test comparatives between groups and a pre-set control, and across groups, respectively. $P$ values less than 0.05 were regarded as significant. Dissolution kinetics parameters were evaluated using Microsoft Excel $2018^{\mathrm{TM}}$ and excel Add-in DD Solver software.

\section{Results and Discussion}

\subsection{Synthesis and characterization (EM, NTA, FTIR, Nitrogen adsorption, and desorption).}

Functionalization of the MSN surface was achieved by post-grafting producing a $2 \%$ and a $5 \%$ PEG $(\mathrm{w} / \mathrm{w})$ formulation. These percentages are considered optimal concentrations of PEG coatings for "stealth" NPs [9,32] to provide enhanced biodistribution and lowered phagocytosis. All MSNs and D-MSNs presented as spherical particles (Figure 1A-D) under TEM, with mean diameters ranging between 37- $66 \mathrm{~nm}$ (Table 1). The PDI range indicated a relatively monodisperse population, while the hydrodynamic diameter (from NTA) ranged between 12-215 $\mathrm{nm}$ (Table 1). The silanol rich MSNs recorded a negative zeta potential, however upon functionalization with the amine-rich CHIT and PEG, the zeta potential increased positively (Table 1). MSN-CHIT recorded a higher net positive charge than the PEGylated MSNs, possibly due to the amphiphilic PEG chains masking some of the CHIT amine groups [27,33]. The hydration corona formed around the PEGylated MSNs, and agglomeration of the weakly charged MSNs could account for variations in the zeta potential. PEGylation is known to form a hydrophilic barrier or "cloud" that masks surface charges and sterically prevents protein adsorption, reducing mono-nuclear phagocytic system (MPS) recognition [34]. Size and zeta potential are regarded as important factors that affect the NPs cellular uptake and its fate in an in vivo system [35]. 

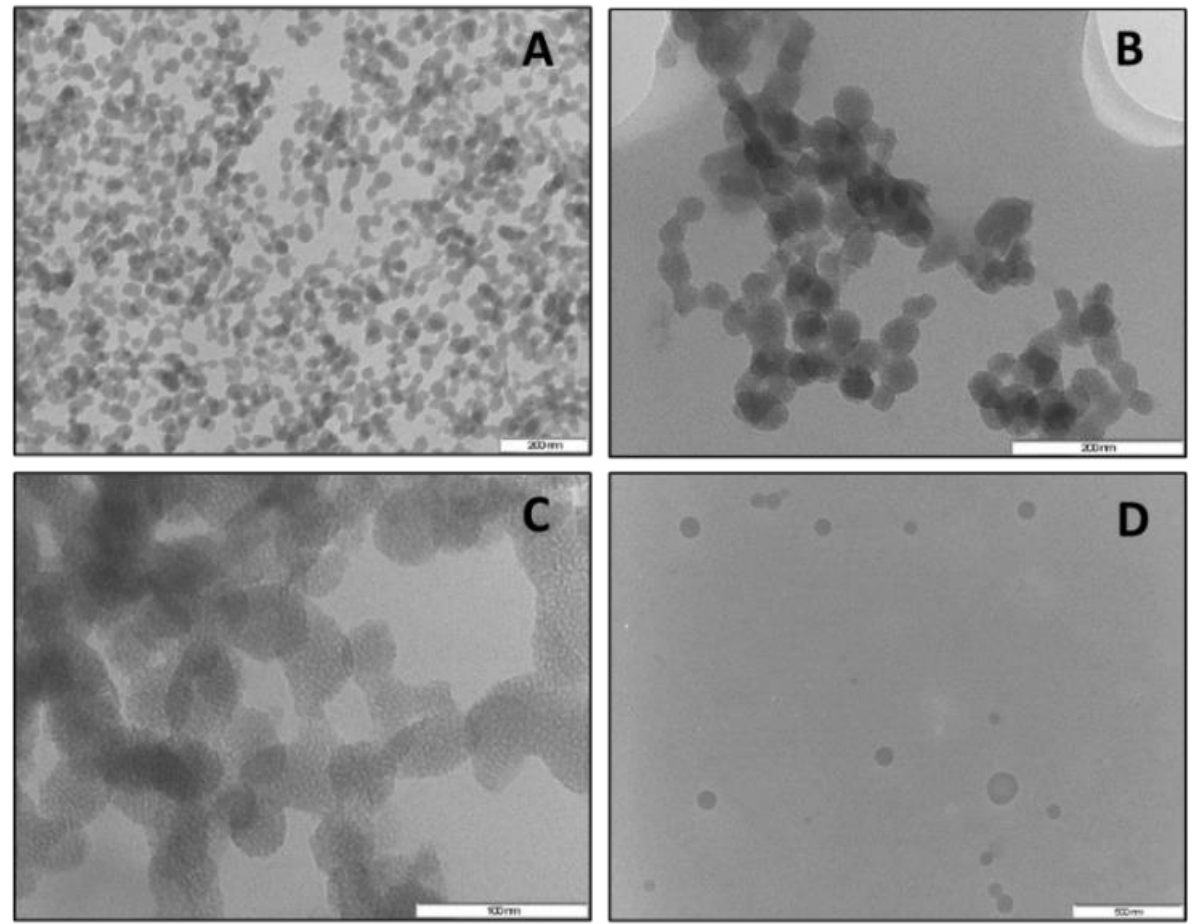

Figure 1. Selected TEM images of (A) MSN, (B) CHIT-MSN, (C) 5\%PEG-CHIT-MSN, and (D) 2\%PEGCHIT-MSN-drug loaded.

Table 1. Size, PDI, and zeta potential of MSN formulations from TEM and NTA studies.

\begin{tabular}{l|l|l|l|l} 
Nanoparticle/Nanocomplex & $\begin{array}{l}\text { Mean Diameter } \\
\mathbf{( T E M )} \\
(\mathbf{n m} \pm \mathbf{S D})\end{array}$ & $\begin{array}{l}\text { PDI } \\
\text { (SD/mean) }\end{array}$ & $\begin{array}{l}\text { Hydrodynamic } \\
\text { Diameter (NTA) } \\
(\mathbf{n m} \pm \text { SD) }\end{array}$ & $\begin{array}{l}\text { Zeta Potential } \\
(\mathbf{m V})\end{array}$ \\
\hline MSN [20,21] & $36.09 \pm 7.08$ & 0.0385 & $188 \pm 51.6$ & $-9.8 \pm 1$ \\
\hline CHIT-MSN [20,21] & $39.43 \pm 7.22$ & 0.0335 & $62.2 \pm 16$ & $32.4 \pm 0.4$ \\
\hline 2\%PEG-CHIT-MSN [20,21] & $40.75 \pm 7.11$ & 0.0422 & $12 \pm 3.3$ & $17.0 \pm 16.5$ \\
\hline 5\%PEG-CHIT-MSN[20,21] & $40.37 \pm 7.70$ & 0.0364 & $54.8 \pm 2.1$ & $7.4 \pm 0.7$ \\
\hline 2\%PEG-CHIT-MSN-D & $66.21 \pm 27.78$ & 0.1760 & $214.7 \pm 51.4$ & $12.7 \pm 0.4$ \\
\hline 5\%PEG-CHIT-MSN- D & $44.45 \pm 5.00$ & 0.0127 & $49.6 \pm 11.9$ & $6.1 \pm 2.8$
\end{tabular}

As per IUPAC classification, the MSNs were mesoporous, displaying a typical type IV $\mathrm{N}_{2}$ adsorption-desorption isotherm. The adsorption-desorption isotherm had two hysteresis lops at $\mathrm{P} / \mathrm{P}_{0}=0.6-0.75$ and $\mathrm{P} / \mathrm{P}_{0}=0.87-0.97$, respectively, supporting evidence mesoporous structure with a narrow size distribution centered at $3.5 \mathrm{~nm}$ (Figure 2).

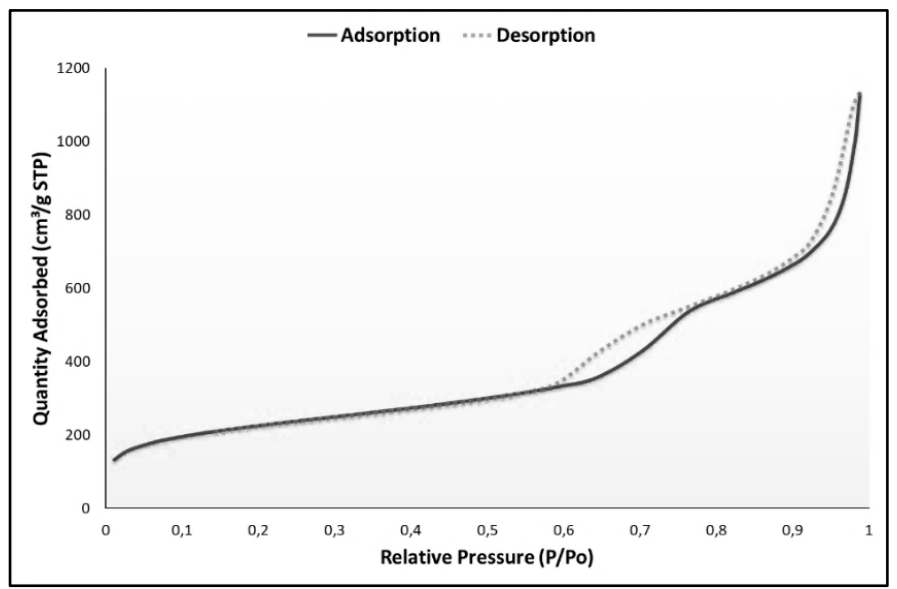

Figure 2. $\mathrm{N}_{2}$ adsorption and desorption isotherm for MSN. 
The surface area was $710.36 \mathrm{~m}^{2} / \mathrm{g}$, and the pore volume to $1.74 \mathrm{~cm}^{2} / \mathrm{g}$. The absorption and microscopic analyses revealed distinctive mesoporous spheres with well-defined pores for drug loading and release. Factors contributing to the rate and magnitude of drug release include desorption [36], diffusion [37], swelling [38], electrostatic interaction [39], size of drug molecules relative to particle surface interactions, and template degradation [40]. These factors can be influenced by $\mathrm{pH}$, temperature, mechanical and enzymatic effects, enabling their application as stimuli-responsive delivery systems [41,42].

The FTIR spectra (Figure 3) indicated absorption peaks at $439 \mathrm{~cm}^{-1}$ for $\mathrm{Si}-\mathrm{O}-\mathrm{Si}$ vibrations. The vibrational peak at $3309 \mathrm{~cm}^{-1}$ is characteristic of a $v \mathrm{Si}-\mathrm{OH}$ stretching in the mesostructured silica particle. The N-H vibrational bands at $1413 \mathrm{~cm}^{-1}$ and $1547 \mathrm{~cm}^{-1}$, indicated the presence of amino groups and the presence of CHIT on the MSN surface. These peaks were correlated to that previously reported $[21,43]$.

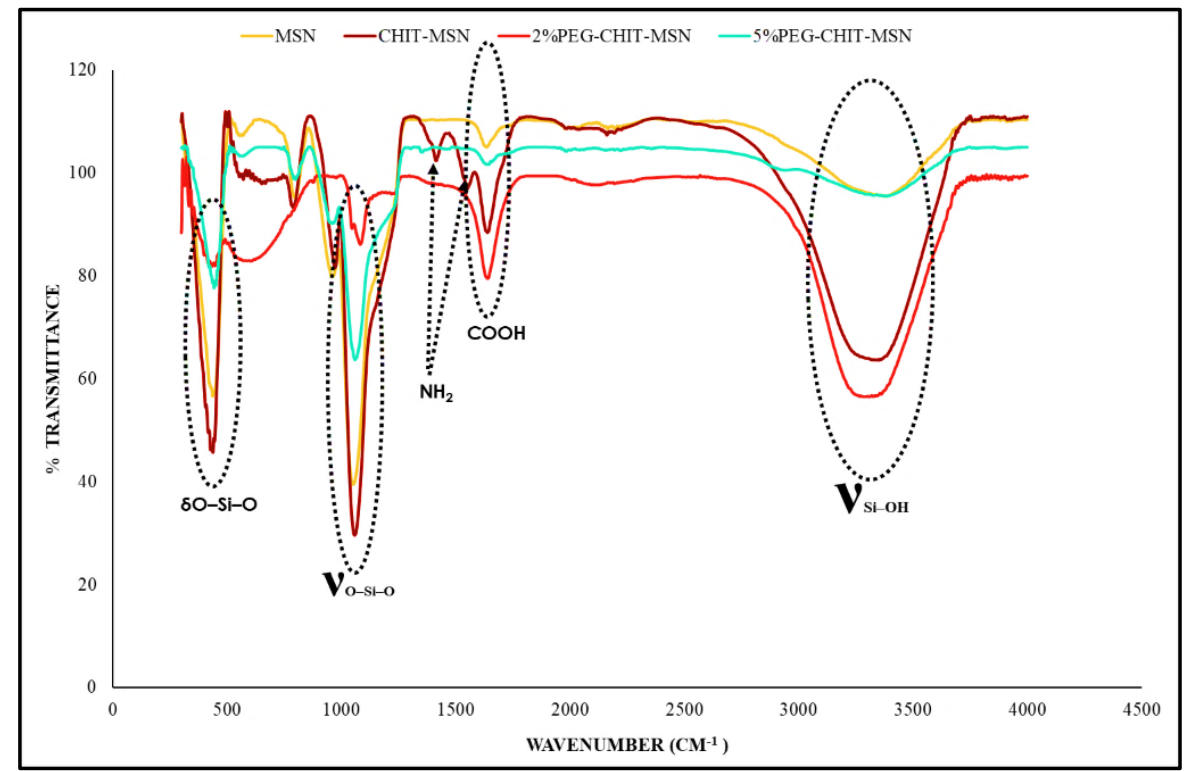

Figure 3. FTIR Spectra of f-MSNs (denoted at the top of the graph). Plain MSNs indicated by the solid yellow line, CHIT-MSN indicated by the dark red line, $2 \%$ PEG - CHIT-MSN indicated by the bright red line, and the cyan line represents $5 \%$ PEG-CHIT-MSN.

\subsection{Efficiency of DOX and 5-FU Co-loading.}

The cylindrical pores of the MSNs were incompletely capped with CHIT and PEG, increasing the hydrophilicity of the MSN, and providing a temporary gated layer entrapping the loaded drugs. DOX loading was $29.4 \%(0.2941 \mathrm{mg})$ and $20.41 \%(0.2041 \mathrm{mg})$, while 5-FU loading was $4.7 \%(0.047 \mathrm{mg})$ and $2.51 \%(0.0251 \mathrm{mg})$ in the $5 \%$ and $2 \%$ PEG-CHIT-MSNs, respectively. This encapsulation efficiency by NPs was lower than that reported for single 5FU or DOX previously $[5,8,20,21,25]$. The low drug encapsulation may be attributed to the dual-loading of electrostatically different drugs, leading to electrostatic repulsions between the PEC superficial coating of the negatively charged MSNs, negatively charged 5-FU molecules, and hydrophobic DOX molecules (neutral under physiological conditions). The hydrophobic DOX molecules hence interacted with the hydrophilic PEG chains on the MSNs, and were internalized at higher loading capacities. Comparatively, 5-FU molecules are attracted to the positively charged amine groups of CHIT and are then internalized. CHIT may have also been covered by a PEG brush, reducing the number of available amino groups and hence the uptake of 5-FU. 
Furthermore, 5-FU, a smaller molecule compared to DOX, is more likely to be trapped in the MSN's outer polymer layer, contributing to a "burst" effect during drug release. A combined drug loading capacity of $20-30 \%$ (w/w) was achieved for the D-MSNs. It was reported that due to differences in the pharmacokinetics of drugs or genes used in combination therapy can lead to low encapsulation efficiencies [44].

\subsection{Drug release and kinetics.}

The release of 5-FU $(\mathrm{pKa}=8)$ is dependent on its interaction with MSN's PEC layer and the $\mathrm{pH}$ of the aqueous medium. As the $\mathrm{pH}$ changes and hydrophilic related shrinking occurs, the entrapped drug is not easily released as it is tightly bound. At $\mathrm{pH} 7.4$, the 2\%PEGCHIT-MSN produced a higher total 5-FU and DOX release of $21 \%$ and $52 \%$ (Figure 4). An initial burst, followed by an exponential rate release, was seen for the first 24 hours, followed by a slow release for up to 72 hours. At $\mathrm{pH} 4.2$, the accumulated 5-FU release was $29 \%$ for 2\%PEG-CHIT-MSN and 59\% for 5\%PEG-CHIT-MSN, with DOX release being higher at $62 \%$ for 2\%PEG-CHIT-MSN and 53\% for 5\%PEG-CHIT-MSN. An initial exponential release in the first $12 \mathrm{~h}$ was followed by a plateaued release for up to $72 \mathrm{~h}$ (Figure 4B). Importantly, there was minimal release at $\mathrm{pH} 7.4$, with a marked increase in the total drug released at the endosomal/lysosomal $\mathrm{pH}$ of 4.2. Overall, the release of both drugs was much higher at $\mathrm{pH} 4.2$.
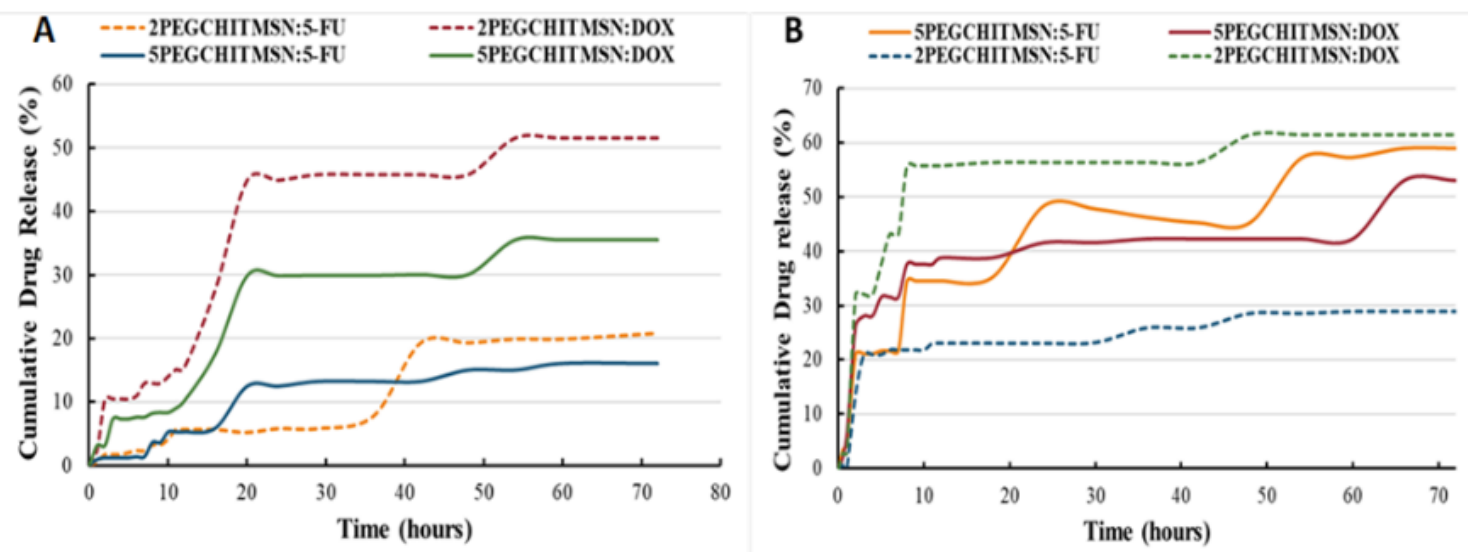

Figure 4. Drug release profile of D-MSNs at (A) $\mathrm{pH}$ 7.4. 2\%PEG-CHIT-MSNs is denoted by a dashed line, DOX release in red and 5-FU released in yellow. 5\% PEG-CHIT-MSNs release is shown as a solid line, with DOX release in green and 5-FU release in blue; (B) $\mathrm{pH}$ 4.2: 2\% PEG-CHIT-MSNs is denoted by a dashed line, with DOX release in green and 5-FU in blue. 5\% PEG-CHIT-MSNs release is shown as a solid line, with DOX release in red and 5-FU in yellow.

Using conventional mathematical kinetic models, multi-mechanistic release patterns for these MSN formulations under in vitro conditions were proposed. The models tested were zero order, first order, Higuchi [45], Hixson-Crowell [46], and Korsmeyer-Peppas [37]. The diffusion and erosion contribution to the release patterns was quantified using the Kopcha [47] model. The constants $\mathrm{A}=$ diffusion and $\mathrm{B}=$ erosion were used to illustrate which of these two factors affected release more mathematically. According to the literature, when $A / B=1$, diffusion and erosion are equal. However, when the $\mathrm{A} / \mathrm{B}<1$, erosion dominates over diffusion, and conversely for $\mathrm{A} / \mathrm{B}>1$, the diffusion is not affected by erosion. The best release model was selected based on the correlation coefficient $\left(\mathrm{R}^{2}\right)$ obtained, and release exponents that described the release patterns were based on the equations below:

Zero Order model: 
First Order model:

$$
M_{t}=M_{0}+k_{0} t
$$

$$
\log M_{t}=\log M_{0}+\frac{k_{1} t}{2.303}
$$

Higuchi model [45]: This model assumes release from an insoluble matrix as a timedependent progression in which Fickian diffusion is supposed.

$$
M_{t}=k_{H} \sqrt{t}
$$

Hixson- Crowell [46] model: This cube root model describes release by dissolution and accounts for changes in the surface area and diameter of the particle.

$$
\left(M_{t}-M_{\infty}\right)^{1 / 3}=k_{H C} \cdot t
$$

Korsmeyer-Peppas [37] model: Follows release from a spherical polymeric system in which there may be diffusion or erosion.

$$
\frac{M_{t}}{M_{\infty}}=k_{K P} \cdot t^{n}
$$

Kopcha model [47]: is used to define the amount of diffusion and erosion and its effects on the release rate.

$$
M_{t}=A \cdot \sqrt{t}+B t
$$

Where $\mathrm{M}_{0}, \mathrm{M}_{\mathrm{t}}$ and $M_{\infty}$ Represent the amount of drug dissolved at time zero, time $t$, and infinite time, respectively. The kinetic constants are represented by $\mathrm{k}$ and subscripted with their model initial. The release exponent, $\mathrm{n}$, is derived from the Korsmeyer-Peppas model and defines the release mechanism of spherical formulations. When $n=1$, the release is of zero-order. When $\mathrm{n}=0.43$, the release is described as Fickian diffusion, with no relevant deformation or stresses during drug release. Quasi-Fickian diffusion is defined when $n<0.43$. When $0.43<\mathrm{n}<0.85$, the release follows anomalous diffusion, with swelling or stress during drug release; which may be due to temperature, activity, or structural dimension related fluctuations. If $n>0.85$,

\begin{tabular}{|c|c|c|c|c|c|c|c|c|c|c|c|c|}
\hline pH & \multicolumn{2}{|c|}{ Zero-order } & \multicolumn{2}{|c|}{ First -order } & \multicolumn{2}{|c|}{ Higuchi's } & \multicolumn{2}{|c|}{ Hixson-Crowell's } & \multicolumn{2}{|c|}{ Korsmeyer-Peppas's } & \multicolumn{2}{|c|}{ Kopcha's } \\
\hline \multicolumn{13}{|c|}{ Correlation value $\left(\mathrm{R}^{2}\right)-2 \%$ PEG-CHIT-MSN-D } \\
\hline \multirow{2}{*}{4.2} & \multirow{2}{*}{0.47} & \multirow{2}{*}{0.85} & \multirow{2}{*}{0.68} & \multirow{2}{*}{0.45} & \multirow{2}{*}{0.62} & \multirow{2}{*}{0.62} & \multirow[b]{2}{*}{0.72} & \multirow[b]{2}{*}{0.47} & 0.85 & 0.77 & \multirow{2}{*}{0.97} & \multirow{2}{*}{0.97} \\
\hline & & & & & & & & & $\mathrm{n}=0.13$ & $\mathrm{n}=0.17$ & & \\
\hline \multirow{2}{*}{7.4} & \multirow{2}{*}{0.91} & \multirow{2}{*}{0.81} & \multirow{2}{*}{0.87} & \multirow{2}{*}{0.75} & \multirow{2}{*}{0.85} & \multirow{2}{*}{0.89} & \multirow{2}{*}{0.61} & \multirow{2}{*}{0.79} & 0.91 & 0.88 & \multirow{2}{*}{0.61} & \multirow{2}{*}{0.81} \\
\hline & & & & & & & & & $\mathrm{n}=0.80$ & $\mathrm{n}=0.61$ & & \\
\hline \multicolumn{13}{|c|}{ Correlation value $\left(\mathrm{R}^{2}\right)$ - 5\% PEG-CHIT-MSN-D } \\
\hline \multirow{2}{*}{4.2} & \multirow{2}{*}{0.80} & \multirow{2}{*}{0.51} & \multirow{2}{*}{0.77} & \multirow{2}{*}{0.72} & \multirow{2}{*}{0.90} & \multirow{2}{*}{0.69} & 080 & 074 & 0.87 & 0.90 & 093 & 098 \\
\hline & & & & & & & 0.80 & 0.74 & $\mathrm{n}=0.27$ & $\mathrm{n}=0.14$ & 0.93 & 0.98 \\
\hline 74 & 085 & 083 & 0.67 & 073 & 0.92 & 090 & 069 & 064 & 0.88 & 0.90 & 034 & 078 \\
\hline & & & & & & & & & $\mathrm{n}=0.94$ & $\mathrm{n}=0.69$ & & \\
\hline
\end{tabular}
there is Case II transport. The release kinetic mathematical expressions (equations 4-9) were applied accordingly (Table 2) based on the released data.

Table 2. Correlation coefficients $\left(\mathrm{R}^{2}\right)$ obtained from drug-loaded 2\% PEG-CHIT-MSNs through release kinetic models at pH 7.4 and 4.2. DOX kinetics is shown in white blocks and 5-FU kinetics in shaded blocks. Yellow shading depicts the calculated Korsmeyer- Peppas release exponential.

DOX, and 5-FU possessed distinct kinetic release mechanisms at each $\mathrm{pH}$, depending on the swelling, diffusion, erosion, and rate release effects specific to polymeric mesoporous delivery vehicles. DOX release at $\mathrm{pH} 7.4$ from 2\% PEG-CHIT-MSN followed anomalous diffusion $\left(n=0.61, R^{2}=0.90\right)$ according to Korsmeyer-Peppas. There was low erosion and diffusion effects $\left(\mathrm{A} / \mathrm{B}>\mathrm{B}\right.$, Kopcha model $\left.\mathrm{R}^{2}=0.78\right)$. 5-FU release at $\mathrm{pH} 7.4$ followed zeroorder kinetics, indicating a constant release over $72 \mathrm{~h}$. According to Korsmeyer-Peppas and 
Kopcha models, the anomalous release was subject to swelling and the MSN matrix stresses. Hence, the hydrophilic layer's interaction with the aqueous medium ( $\mathrm{pH}$ 7.4) may have caused swelling resulting in a controlled release of 5-FU.

At $\mathrm{pH} 4.2$, DOX and 5-FU release from the 2\% PEG-CHIT-MSN followed Fickian diffusion and had negligible erosion effects $\left(n=0.14 ; R^{2}=0.90\right.$ and $n=0.27, R^{2} 0.87$ ) (Table 2). DOX release from 5\%PEG-CHIT-MSN fitted the Korsmeyer-Peppas and Kopcha's release models $\left(\mathrm{R}^{2}=0.90\right.$ and 0.98$)$, while the release exponent $(n=0.14)$ suggested that the release followed Fickian diffusion with minor swelling or friction affecting drug release. Supporting the Korsmeyer- Peppas findings, the Kopcha model defined A/B values larger than B, indicating release through Fickian diffusion with fewer erosion effects.

DOX release at $\mathrm{pH} 7.4$ followed Higuchi and Korsmeyer-Peppas models with $\mathrm{R}^{2}=0.90$ (Table 3), suggesting anomalous diffusion subject to swelling and stresses to the matrices. Using Kopcha's model, the A/B value was larger than the erosion of constant B. The diffusion and erosion constants were similar and played a co-supporting role during DOX release from the 5\% PEG-CHIT-MSN. The interaction of DOX with the MSN matrix and aqueous medium, together with the $\mathrm{pH}$ and the ionization of the PEC polymer coating on the MSNs may have contributed to a slower diffusion rate. The low 5-FU release is possibly due to its entrapment within the PEC on the MSN surface. At both pHs, FU release from 5\%PEG-CHIT-MSN, followed Higuchi's model, with MSN swelling not affecting a release. At $\mathrm{pH} 4.2$, 5-FU release showed Fickian-diffusion, with negligible erosion affecting the release rate $(\mathrm{A} / \mathrm{B}>\mathrm{B}, \mathrm{Kopcha}$ 's $\left.\mathrm{R}^{2}=0.93\right)$. Both polymerized MSNs seem to be favorable controlled drug release platforms. Their selective release of the bound drug upon cellular uptake was related to a drop in $\mathrm{pH}$ seen in endosomal and lysosomal vesicles, especially cancer cells, with low cytosolic pHs due to increased anaerobic metabolism [48]. These MSNs may passively target tumor cells rather than healthy tissue, reducing the toxicities and side-effects of conventional chemotherapeutics.

Table 3. Korsmeyer-Peppas model's release exponent factor and corresponding Kopcha release model results. DOX kinetics are shown in non-shaded blocks and 5-FU kinetics in shaded blocks.

pH 7.4

\begin{tabular}{l|l|l|l|l}
\hline Multi-drug formulation & Korsmeyer- Peppas Model & \multicolumn{3}{l}{ Kopcha Model } \\
\hline & $\mathrm{n}-$ value & $\mathrm{A}$ & $\mathrm{B}$ & $\mathrm{A} / \mathrm{B}$ \\
\hline \multirow{2}{*}{ 2\%PEG-CHIT-MSN } & 0.80 & 0.51 & 0.22 & 2.31 \\
\cline { 2 - 6 } & 0.61 & 2.75 & 0.64 & 4.30 \\
\hline \multirow{2}{*}{$5 \%$ PEG-CHIT-MSN } & 0.94 & 0.47 & 0.25 & 1.88 \\
\cline { 2 - 6 } & 0.69 & 2.61 & 0.31 & 8.41 \\
\hline
\end{tabular}

\begin{tabular}{l|l|l|l|l}
\hline Multi-drug formulation & Korsmeyer- Peppas Model & \multicolumn{3}{l}{ Kopcha Model } \\
\hline & $\mathrm{n}-$ value & $\mathrm{A}$ & $\mathrm{B}$ & $\mathrm{A} / \mathrm{B}$ \\
\hline \multirow{2}{*}{$2 \%$ PEG-CHIT-MSN } & 0.13 & 12.36 & 1.35 & 9.16 \\
\cline { 2 - 6 } & 0.17 & 23.50 & 2.20 & 10.68 \\
\hline \multirow{2}{*}{$5 \%$ PEG-CHIT-MSN } & 0.27 & 14.19 & 1.140 & 12.45 \\
\cline { 2 - 6 } & 0.14 & 19.59 & 2.160 & 9.069
\end{tabular}

\subsection{Cell viability.}

MSNs have exhibited biocompatibility and positive pharmacokinetic behavior in biological systems [49]. The cell viability results confirmed a dose-dependent effect. MSNs and D-MSNs were non-toxic to the control HEK293 cells even at high doses, with proliferation observed at low concentrations $(20-50 \mu \mathrm{g} / \mathrm{mL}$ ) (Figure 5A). HEK293 cells possessed similar architecture, biochemical pathways, and metabolic processes as normal dividing cells and were used as a representative model of normal healthy cells [50]. Caco- 2 cells were used to simulate the small intestinal epithelial lining [51] and showed no significant cytotoxicity compared to 
the free drug (Figure 5B). In the MCF-7 and the HeLa cells (Figures 5C,D), significant cytotoxicity was observed, indicating the drugs' cell-specific delivery by the MSNs, which is supported by the apoptosis and cell cycle analyses.

Polymerization resulted in increased biocompatibility and lower cytotoxicity of the DMSNs in normal cells, corresponding to published reports of low toxicity and immunogenicity of MSNs in biological systems [20,21]. Supporting evidence from the drug release studies, which proposed the slow-controlled $\mathrm{pH}$-dependent release of DOX and 5-FU at higher concentrations, with over $90 \%$ of the drug released after 48 hours, reinforced the cytotoxicity observed in vitro.

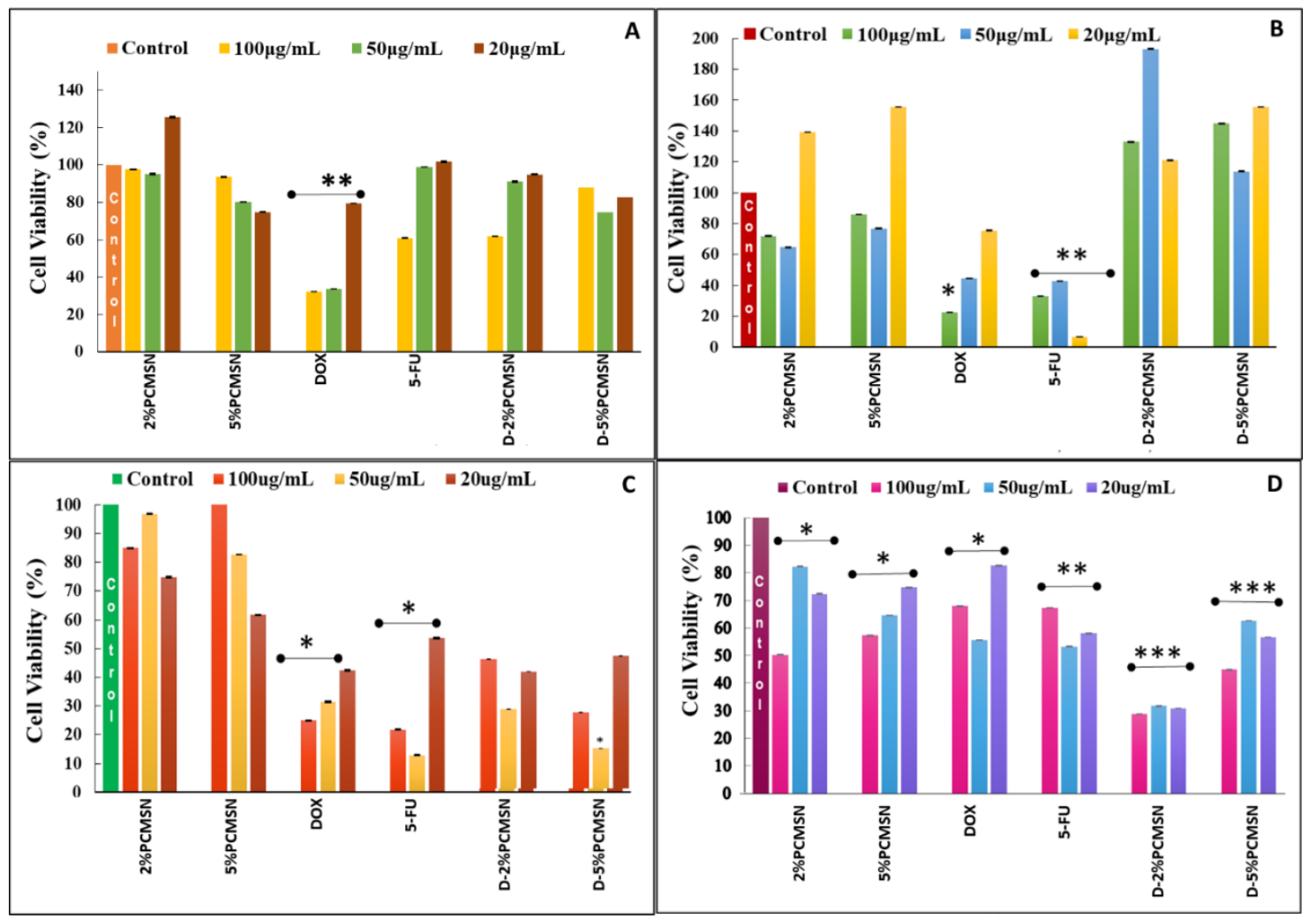

Figure 5. MTT assays of MSNs and D-MSNs at various concentrations (20, 50, and $100 \mu \mathrm{g} / \mathrm{mL})$ in (A) HEK293 cells, (B) Caco-2 cells, (C) MCF-7 cells, and HeLa cells. Data are represented as mean \pm SD $(n=3)$ * $\mathrm{p}<0.05$ and $* * \mathrm{p}<0.01$ considered statistically significant.

\subsection{Apoptosis and cell cycle assays.}

Selected apoptosis images are reflected in Figure 6. AO/EB staining revealed many bright orange fluorescing cells with loss of surface adherence, indicating morphological changes such as membrane blebbing, apoptotic bodies, nuclear condensation, and fragmentation. Overall, the Caco-2 cells showed drug-induced apoptosis at varying degrees, with early apoptotic cells fluorescing bright yellow, while in the HeLa and MCF-7 cells, the 2\%PEG-CHIT-MSN-D induced the greatest apoptosis. DNA condensation and DNA fragmentation, suggesting early apoptosis, were also observed for the Caco-2 cells.

Cell death may be induced during mitosis, particularly during the metaphase/anaphase transition, with apoptosis occurring due to mitotic spindle defects or a self-conserving process that prevents aneuploidy or chromosomal deficiencies leading to oncogenesis [52,53]. Hence, the cell cycle's transition and arrest are important in deducing DNA damage, activation of normal cell repair mechanisms, or induction of apoptosis. The number of cells within the $\mathrm{G}_{1} / \mathrm{S}$ 
or $\mathrm{G}_{2} / \mathrm{M}$ phases is indicative of cells that have initiated the DNA damage response (DDR), and repair pathways in response to the addition of DNA-targeting chemotropic drugs. For MCF-7 and HeLa cells, the control population was well-distributed in the $\mathrm{G}_{1}, \mathrm{G}_{2}, \mathrm{~S}$, and $\mathrm{M}$ phases. The increased MCF-7 cell populations in the $\mathrm{S}$ and $\mathrm{G}_{2} / \mathrm{M}$ phases indicated DNA damage and cell cycle arrest and correlated to the high number of apoptotic and fragmented cells seen after dual AO/EB staining and the cytotoxicity at low D-MSN dosages.
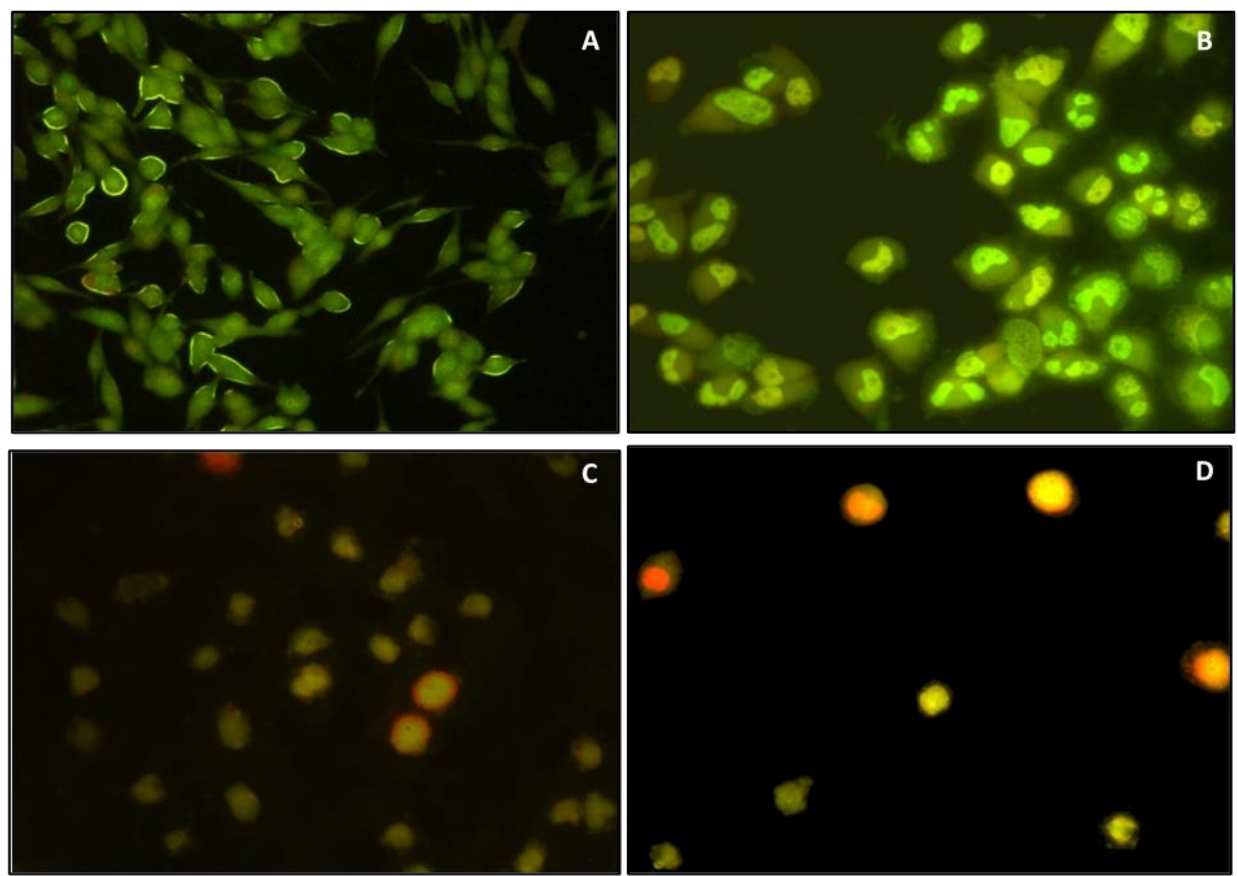

Figure 6. Fluorescent images (20 x magnification) of A) HEK293 treated with 2\%PEG-CHIT-MSN, B) Caco-2 treated D-2\%PEG-CHIT-MSN, C) MCF-7 treated with 5\%PEG-CHIT-MSN and, D) HeLa treated with 2\%PEG-CHIT-MSN.



Figure 7. Cell cycle distribution in A) HEK293, B) Caco-2, C) MCF-7, and D) HeLa cells treated with DMSNs. Results are expressed as a percentage ratio of cells found in the three cell cycles after treatment.

Upon D-MSN administration, more HeLa cells were evident in the $\mathrm{G}_{0} / \mathrm{G}_{1}$ phases than in the $S$ and $G_{2} / M$ phases, suggesting $G_{1}$ arrest in HeLa cells, the first checkpoint cells enter. 
There was an increase in the cell population within the limits of DDR-linked phases and an increase in apoptotic and dead cells (Figure 7). No significant cell distribution changes within the three cell cycle phases in the Caco-2 and HEK293 cells were observed, indicating that there was no significant apoptosis.

\section{Conclusions}

The future of therapeutic strategies in the fight against cancer requires a novel and integrated approach providing improved efficiency and reduced side-effects. In this study, stable nano-sized polymeric-MSNs were successfully co-loaded with two therapeutic drugs, producing no negative effects in normal cells but significant anticancer activity in breast and cervical cancer cells. Overall, these drug nanoconjugates were biocompatible. The MSNs acted synergistically with their multi-drug cargo and showed a tendency for passive uptake into the tumor environment. Optimization and clinical translation of this nano-drug system remains to be addressed, but these favorable results warrant investigation in an in vivo model. The observed biological activity and the biocompatibility of these MSNs in vitro look optimistic for cancer therapy, especially in breast and cervical cancers.

\section{Funding}

This research was funded by the National Research Foundation (South Africa), grant numbers $113850 / 120455$.

\section{Acknowledgments}

The authors acknowledge colleagues of the Nano-Gene and Drug Delivery group for continued support.

\section{Conflicts of Interest}

The authors declare no conflict of interest.

\section{References}

1. Siegel, R.L.; Miller, K.D.; Jemal, A. Cancer Statistics, 2019. CA-Cancer J. Clin. 2019, 69, 7-34, https://doi.org/10.3322/caac.21551.

2. Baudino, T. Targeted Cancer Therapy: The Next Generation of Cancer Treatment. Curr. Drug Discov. Technol. 2015, 12, 3-20, https://doi.org/10.2174/1570163812666150602144310.

3. Hanahan, D.; Weinberg, R.A. Hallmarks of cancer: the next generation. Cell 2011, 144, 646-674, https://doi.org/10.1016/j.cell.2011.02.013.

4. Padayachee, J.; Daniels, A.N.; Balgobind, A.; Ariatti, M,; Singh, M. HER-2/neu and MYC gene silencing in breast cancer: Therapeutic potential and advancement in non-viral nanocarrier systems. Nanomedicine 2020, 15, 1437-1452, https://doi.org/10.2217/nnm-2019-0459.

5. Maney, V.; Singh, M. The synergism of Platinum-Gold bimetallic nanoconjugates enhance 5-Fluorouracil delivery in vitro. Pharmaceutics 2019, 11, https://doi.org/10.3390/pharmaceutics11090439.

6. Iwamoto, T. Clinical Application of Drug Delivery Systems in Cancer Chemotherapy: Review of the Efficacy and Side Effects of Approved Drugs. Biol. Pharm. Bull. 2013, 36, 715-718, https://doi.org/10.1248/bpb.b12-01102.

7. Sleight, P.; Pouleur, H.; Zannad, F. Benefits, challenges, and registerability of the polypill. Eur. Heart J. 2006, 27, 1651-1656, https://doi.org/10.1093/eurheartj/ehi841.

8. Akinyelu, J.; Singh, M. Folate-tagged chitosan functionalized gold nanoparticles for enhanced delivery of 5-fluorouracil to cancer cells. Appl. Nanosci. 2019, 9, 7-17, https://doi.org/10.1007/s13204-018-0896-4.

9. Daniels A.N.; Singh, M. Sterically stabilised siRNA:gold nanocomplexes enhance c-MYC silencing in a breast cancer cell model. Nanomedicine 2019, 14, 1387-1401, https://doi.org/10.2217/nnm-2018-0462. 
10. Mbatha, L.S.; Maiyo, F.C.; and Singh, M. Dendrimer Functionalized Folate-Targeted Gold Nanoparticles for Luciferase Gene Silencing in vitro: A Proof of Principle Study. Acta Pharm. 2019, 69, 49-61, https://doi.org/10.2478/acph-2019-0008.

11. Elahi, N.; Kamali, M.; Baghersad, M.H. Recent biomedical applications of gold nanoparticles: A review. Talanta 2018,184, 537-556, https://doi.org/10.1016/j.talanta.2018.02.088.

12. Geetanjali.; Sharma, P.K.; Malviya, R. Toxicity and application of nano-silver in multi-drug resistant therapy. Lett. Appl. NanoBioSci. 2020, 9, 824-829, https://doi.org/10.33263/LIANBS91.824829.

13. Hepokur, C.; Kariper,I.A.; Misir,S.; Ay, E.; Tonoğlu, S.; Ersez, M.S.; Zeybek,U.; Kuruca, S.E.; Yaylim, I. Silver nanoparticle/capecitabine for breast cancer cell treatment. Toxicol. in Vitro 2019, 61, https://doi.org/10.1016/j.tiv.2019.104600.

14. Pathak, J.; Sonker, A.S.; Ragneesh; Singh ,V.; Kumar, D.; Sinha, R.P. Synthesis of silver nanoparticles from extracts of Scytonema geitleri HKAR-12 and their in vitro antobacterial and antitumor potentials. Lett. Appl. NanoBioSci. 2019, 8, 576-585, https://doi.org/10.33263/LIANBS83.576585.

15. Balcomb, B.; Singh, M.; Singh, S. Synthesis and Characterization of Layered Double Hydroxides and their potential as non-viral Gene Delivery Vehicles. ChemistryOpen 2015, 4, 137-145, https://doi.org/10.1002/open.201402074.

16. Nundkumar, N.; Singh, S.; Singh, M. Amino Acid Functionalized Hydrotalcites for Gene Silencing. J. Nanosci. Nanotechnol. 2020, 20, 3387-3397, https://doi.org/10.1166/jnn.2020.17420.

17. Maiyo, F.; Singh, M. Selenium Nanoparticles: Potential in Cancer Gene and Drug Delivery. Nanomedicine 2017, 12, 1075-1089, https://doi.org/10.2217/nnm-2017-0024.

18. Maiyo, F.; Singh, M. Folate-Targeted mRNA Delivery Using Chitosan Functionalized Selenium Nanoparticles: Potential in Cancer Immunotherapy. Pharmaceuticals 2019, 12, https://doi.org/10.3390/ph12040164.

19. Maiyo, F.; Singh M. Polymerized Selenium nanoparticles for Folate-Receptor Targeted Delivery of antiLuc-siRNA: Potential for Gene Silencing. Biomedicines 2020, 8 , http://dx.doi.org/10.3390/biomedicines8040076.

20. Moodley, T.; Singh, M. Polymeric Mesoporous Silica Nanoparticles for enhanced delivery of 5-Fluorouracil in vitro. Pharmaceutics 2019, 11, https://doi.org/10.3390/pharmaceutics11060288.

21. Moodley, T., Singh, M. Sterically Stabilised Polymeric Mesoporous Silica Nanoparticles Improve Doxorubicin Efficiency: Tailored Cancer Therapy. Molecules 2020, 25, https://doi.org/10.3390/molecules25030742.

22. Tang, F.; Li, L.; Chen, D. Mesoporous Silica Nanoparticles: Synthesis, Biocompatibility and Drug Delivery. Adv. Mater. 2012, 24, 1504-1534, https://doi.org/10.1002/adma.201104763.

23. Mngadi, S.M.; Mokhosi, S.R.; Singh, M. Surface-coating of Mg0.5Co0.5Fe2O4 nanoferrites and their in vitro cytotoxicity. Inorg. Chem. Commun. 2019, 108, https://doi.org/10.1016/j.inoche.2019.107525.

24. Vallabani, N.S.; Singh, S. Recent advances and future prospects of iron oxide nanoparticles in biomedicine and diagnostics, 3 Biotech. 2018, 8, https://doi.org/10.1007/s13205-018-1286-z.

25. Maney, V.; Singh, M. An in vitro assessment of Chitosan/ Bimetallic PtAu nanocomposites as delivery vehicles for Doxorubicin. Nanomedicine 2017, 12, 2625-2640, https://doi.org/10.2217/nnm-2017-0228.

26. Hadjesfandiari, N.; Parambath, A. Stealth coatings for nanoparticles: Polyethylene glycol alternatives. In: Engineering for Biomaterial for Drug Delivery Systems. Parambath, A. Ed. Woodhead Publishing, Duxford, UK, 2018; pp.345-361, https://doi.org/10.1016/B978-0-08-101750-0.00013-1.

27. Mishra, P.; Nayak, B.; Dey, R.K. PEGylation in anticancer therapy: An overview. Asian J. Pharm. Sci. 2016, 11, 337-348, https://doi.org/10.1016/j.ajps.2015.08.011.

28. Mohammed, M.A.; Syeda, J.T.M.; Wasan, K.M.; Wasan, E.K. An overview of chitosan nanoparticles and its application in non-parenteral drug delivery. Pharmaceutics 2017, 9, https://doi.org/10.3390/pharmaceutics9040053.

29. Buranachai, T.; Praphairaksit, N.; Muangsin, N. Chitosan/Polyethylene Glycol Beads Crosslinked with Tripolyphosphate and Glutaraldehyde for Gastrointestinal Drug Delivery. AAPS Pharm. Sci .Tech. 2010, 11, 1128-1137, https://doi.org/10.1208/s12249-010-9483-z.

30. Barrett, E.P.; Joyner, L.G.; Halenda, P. The determination of pore volume and area distribution in porous substances. I. Computations from Nitrogen Isotherms. J. Am. Chem. Soc. 1951, 73, 373-380, https://doi.org/10.1021/ja01145a126.

31. Mosmann, T. Rapid colorimetric assay for cellular growth and survival: application to proliferation and cytotoxicity assays. J. Immunol. Meth. 1983, 65, 55-63, https://doi.org/10.1016/0022-1759(83)90303-4.

32. Mosqueira, V.C.F.; Legrand, P.; Gulik, A.; Bourdon, O.; Gref, R.; Labarre, D.; Barrat, G. Relationship between complement activation, cellular uptake and surface physicochemical aspects of novel PEGmodified nanocapsules. Biomater. 2001, 22, 2967-2979, https://doi.org/10.1016/s0142-9612(01)00043-6.

33. Jokerst, J. V.; Lobovkina, T.; Zare, R.N.; Gambhir, S.S. Nanoparticle PEGylation for imaging and therapy. Nanomedicine 2011, 6, 715-728, https://doi.org/10.2217/nnm.11.19.

34. Narainpersad, N.; Singh, M.; Ariatti, M. Novel Neo Glycolipid: Formulation into Pegylated Cationic Liposomes and Targeting of DNA Lipoplexes to the Hepatocyte-Derived Cell Line HepG2. Nucleosides, Nucleotides Nucleic Acids 2012, 31, 206-223, http://dx.doi.org/10.1080/15257770.2011.649331. 
35. Oladimeji, O.; Akinyelu, J.; Singh, M. Nanomedicines for subcellular targeting: the mitochondrial $\begin{array}{llllll}\text { perspective. } \quad \text { Curr. } & \text { Med. } & \text { Chem. } & \text { 2020, } & \text { 27, } & \text { 5480-5509, }\end{array}$ https://doi.org/10.2174/0929867326666191125092111.

36. Srikar,R.; Yarin, A.L.; Megaridis, C.M.; Bazilevsky, A.V.; Kelley, E. Desorption-limited mechanism of release from polymer nanofibers. Langmuir 2008, 24, 965-974, https://doi.org/10.1021/la702449k.

37. Korsmeyer, R.W.; Lustig, S.R.; Peppas, N.A. Solute and penetrant diffusion in swellable polymers I Mathematical modeling. J. Polym. Sci. B Polym. Phys. 1986, 24, 395-408, https://doi.org/10.1002/polb.1986.090240214.

38. Wan, L.S.C.; Heng, P.W.S.; Wong, L.F. Relationship between swelling and drug release in an hydrophilic matrix. Drug Dev. Ind. Pharm. 1993, 19, 1201-1210, https://doi.org/10.3109/03639049309063012

39. Huang, Y.; Yu, H.; Xiao, C. pH-sensitive cationic guar gum/poly (acrylic acid) polyelectrolyte hydrogels: swelling and in vitro drug release. Carbohydr. Polym. 2007, 69, 774-783, https://doi.org/10.1016/j.carbpol.2007.02.016.

40. Popat, A.; Hartono, S.B.; Stahr, F.; Liu, J.; Qiao, S.Z.; Lu, G.Q. Mesoporous silica nanoparticles for bioadsorption, enzyme immobilisation, and delivery carriers. Nanoscale 2011, 3, 2801-2818.

41. Bilalis, P.; Tziveleka, L.A.; Varlas, S.; Iatrou, H. pH-Sensitive nanogates based on poly(l-histidine) for controlled drug release from mesoporous silica nanoparticles. Polym. Chem. 2016, 7, 1475-1485, https://doi.org/10.1039/C1NR10224A.

42. Zhu, J.; Niu, Y.; Li, Y.; Gong, Y.; Shi, H.; Huo, Q.; Liu, Y.; Xu, Q. Stimuli-responsive delivery vehicles based on mesoporous silica nanoparticles: recent advances and challenges. J. Mater. Chem. B 2017, 5, 13391352, https://doi.org/10.1039/c6tb03066a.

43. Beganskiene, A.; Sirutkaitis, V.; Kurtinaitiene, M.; Juskenas, R.; Kareiva, A. FTIR, TEM, and NMR Investigations of Stober Silica Nanoparticles. Mater. Sci. 2004, 10, 287-290.

44. Kesse ,S.; Boakye-Yiadom, K.O.; Belynda Owoya Ochete, B.O.; Opoku-Damoah, Y.; Akhtar, F.; Filli, M.S.; Farooq, M.S.; Aquib, M.; Mily, B.J.M.; Murtaza, G.; Wang, B. Mesoporous Silica Nanomaterials: Versatile Nanocarriers for Cancer Theranostics and Drug and Gene Delivery. Pharmaceutics 2019, 11, https://doi.org/10.3390/pharmaceutics11020077.

45. Higuchi, W.I. Diffusional models useful in biopharmaceutics drug release rate processes. J. Pharm. Sci. 1967, 56, 315-324, https://doi.org/10.1002/jps.2600560302.

46. Hixson, A.W.; Crowell, J.H. Dependence of Reaction Velocity upon surface and Agitation. Ind Eng Chem.1931, 23, 923-931, https://doi.org/10.1021/ie50260a018.

47. Kopcha, M.; Tojo, K.J.; Lordi, N.G. Evaluation of Methodology for Assessing Release Characteristics of Thermosoftening Vehicles. J. Pharm. Pharmacol. 1990, 42, 745-751, https://doi.org/10.1111/j.20427158.1990.tb07014.x.

48. DeBerardinis, R.J.; Lum. J.J.; Hatzivassiliou, G.; Thompson, C.B. The Biology of Cancer: Metabolic Reprogramming Fuels Cell Growth and Proliferation. Cell Metab. 2008, 7, 11-20, https://doi.org/10.1016/j.cmet.2007.10.002.

49. Lu, J.; Liong, M.; Li, Z.; Zink, J.I.; Tamanoi, F. Biocompatibility, Biodistribution, and Drug-Delivery Efficiency of Mesoporous Silica Nanoparticles for Cancer Therapy in Animals. Small 2010, 6, 1794-1805, https://doi.org/10.1002/smll.201000538.

50. Thomas, P.; Smart, T.G. HEK293 cell line: A vehicle for the expression of recombinant proteins. $J$. Pharmacol. Toxicol. Methods 2005, 51, 187-200, https://doi.org/10.1016/j.vascn.2004.08.014.

51. Artursson, P.; Karlsson, J. Correlation between oral drug absorption in humans and apparent drug permeability coefficients in human intestinal epithelial (Caco-2) cells. Biochem. Biophys Res Commun. 1991, 175, 880-885, https://doi.org/10.1016/0006-291x(91)91647-u.

52. Castedo, M.; Perfettini, J-L.; Roumier, T.; Andreau, K.; Medema, R.; Kroemer, G. Cell death by mitotic catastrophe: a molecular definition. Oncogene 2004, 23, 2825-2837, https://doi.org/10.1038/sj.onc.1207528.

53. Vakifahmetoglu, H.; Olsson, M.; Zhivotovsky, B. Death through a tragedy: mitotic catastrophe. Cell Death Differ. 2008, 15, 1153-1162, https://doi.org/10.1038/cdd.2008.47. 